\title{
A prospective randomised controlled study on the effects of myoinositol on ovarian functions and metabolic factors in women with polycystic ovarian syndrome
}

\author{
Pooja Singh*, Suchismita Biswal, Santosh Kumar Verma
}

Department of Obstetrics and Gynecology, The West Bengal University of Health Sciences, Kolkata, West Bengal, India

Received: 22 February 2018

Revised: 30 October 2020

Accepted: 31 October 2020

\author{
*Correspondence: \\ Dr. Pooja Singh, \\ E-mail: pooja.nrs@gmail.com
}

Copyright: (c) the author(s), publisher and licensee Medip Academy. This is an open-access article distributed under the terms of the Creative Commons Attribution Non-Commercial License, which permits unrestricted non-commercial use, distribution, and reproduction in any medium, provided the original work is properly cited.

\section{ABSTRACT}

Background: Polycystic ovary syndrome is one of the most common endocrine disorder affecting five to ten percent women of reproductive age group. Myoinositol has been reported to be helpful in PCOS women with deranged metabolic and ovarian factors. In this study, we have evaluated the effects of myoinositol in women with PCOS.

Methods: A total of 132 patients are included in the study. 66 patients in the study group were given myoinositol 4 gm daily for three months, while other 66 patients in the control group were given folic acid for the same duration. The parameters were evaluated at the beginning, six and twelve weeks after intervention.

Results: After completion of 12 weeks, myoinositol was found to have a significant effect on reduction of BMI of the patients. No changes was seen in the fasting insulin levels, but a significant decrease in fasting blood sugar levels of patients was seen. Also, a significant increase in serum HDL was seen in the study group. Luteal phase serum progesterone was also increased in the study group.

Conclusions: Myoinositol has got noticeable effects in reducing the BMI of PCOS women. We didn't find any significant effect of the drug over the fasting insulin level. Serum HDL was increased in some patients. An increase in luteal phase progesterone was noticed which suggest that myoinositol may be beneficial in ovulation. However further studies are needed to establish the same.

Keywords: Myoinositol, Polycystic ovarian syndrome

\section{INTRODUCTION}

Polycystic ovarian syndrome (PCOS) is one of the most common endocrine disorder affecting five to ten percent women of reproductive age group. ${ }^{1}$ Typically PCOS is characterized by hyperandrogenism, chronic anovulation, polycystic ovaries at ultrasound evaluation and dermatological problems such as acne, hirsutism and seborrhoea. ${ }^{2}$ It is one of the most common cause of female infertility. ${ }^{3}$ The hallmark of this condition is excess androgen production, mainly by the ovaries. This excess androgen interferes with the reproductive, endocrine and metabolic functions of the body. Women with PCOS usually suffer from infertility and menstrual cycle disorder extending from oligomenorrhoea to amenorrhoea. In addition, PCOS women, in the long run, are found to be at increased risk of metabolic complications like diabetes hypertension, dyslipidaemia, cerebrovascular and cardiovascular accidents.

The etiology of PCOS mostly remains unknown. In addition to the abnormal hormonal parameters such as LH FSH ratio, there is an important role of altered insulin resistance in many PCOS cases. ${ }^{4,5}$ A genetic/familiar predisposition is also said to the cause behind this insulin resistance. ${ }^{6}$ This condition, if remains untreated, will 
ultimately lead to impaired glucose tolerance in 30-40\% PCOS women, may leading to diabetes also.

Several studies suggest that some abnormal action of insulin might be dependent from the inositolphosphoglycan (IPG) mediators of insulin action and suggest that a deficiency in a specific D-chiroinositol (DCI)- containing IPG may underlie insulin resistance, similarly to type 2 diabetes. $^{7}$

Environmental and genetic factors also have a role in the development of PCOS. Some studies suggest that ovarian theca cells in PCOS-affected women are more capable to convert androgenic precursors to testosterone than in other women. ${ }^{8}$ The treatment of PCOS women depends on the clinical presentation. In a young lady, this usually involves regularization of cycles and/or the requirement for ovulation induction. For ovulation induction, several methods have been proposed which includes- weight loss, exercise and lifestyle modifications, clomiphene citrate, metformin, gonadotropins, ovarian drilling and IVF. However, the long-term consequences of PCOS deserves special care and monitoring throughout life either to minimize or to avoid the related complications altogether. D-chiro-inositol (DCI)- administration has been demonstrated to reduce insulin resistance both in lean and obese PCOS patients. Also, it helps in improving ovarian function and decreasing hyperandrogenism. ${ }^{9,10}$ Another inositol, myoinositol has been reported to be greatly correlated to ovarian function and oocyte quality in patients undergoing in vitro fertilization (IVF) procedures, independently from circulating plasma levels. ${ }^{10,11}$

Myoinositol is the most abundant form of inositol-a vitamin B like substance. It is a key intracellular signaling molecule responsible for optimal cellular glucose regulation, osmolarity and cell membrane integrity. Its deficiency is related to the pathology of insulin resistance, hyperlipidemia, deranged hormonal levels and poor ovulation in women with PCOS. In a few cohort studies' it was observed that myoinositol is beneficial in PCOS women. ${ }^{10-14}$ Furthermore, elevated concentrations of myoinositol in human follicular fluid play a role in follicular maturity and provide a marker of good-quality oocytes. ${ }^{12,13}$ Previous studies have demonstrated that this drug is capable of restoring spontaneous ovarian activity, and consequently fertility, in most patients with PCOS. ${ }^{14}$

The purpose of this study was to evaluate the effects of myoinositol on ovarian function and metabolic factors in women with PCOS.

\section{METHODS}

\section{Study type}

This was a prospective randomized single blinded interventional study.

\section{Study area}

Patients attending the OPD of gynaecology and obstetrics at Ramakrishna Mission Seva Pratishthan (VIMS), Kolkata.

Study period: April 2013 to August 2014.

\section{Selection criteria}

All PCOS patients who satisfy our inclusion criteria and willingly agree to participate in the study are included in the study. Considering alpha error of the study to be $5 \%$ and power of the study to be $90 \%$, a total of 60 patients were required in each arm (study and control). Taking the dropout rate of $10 \%$, a total of 132 patients (66 in each arm) were included in the study.

Randomisation was performed by using a pretested random number table. Out of 132 women, 66 women were randomly selected into the study group and the other 66 were taken into the control group.

\section{Inclusion criteria}

Women satisfying "The Rotterdams criteria" for diagnosis of PCOS; no other known causes of infertility; no known metabolic disorder.

\section{Exclusion criteria}

Women less than 18 years or more than 40 years old; patients on hormonal medication; history of some addiction.

\section{Procedure}

Sixty-six patients in the study group were given myoinositol $4 \mathrm{gm}$ daily for three months, while other sixty-six patients in the control group were given folic acid tablets $(5 \mathrm{mg})$ for the same duration. The parameters to be studied were evaluated at the beginning of intervention and six and twelve weeks after intervention. A trend in changes of the parameters were noted. Following are the parameters studied:

General factors: BMI, waist hip ratio, blood pressure.

Metabolic factors: Serum fasting insulin, fasting blood sugar, lipid profile (Total cholesterol, Triglycerides, HDL and LDL).

Ovarian factors: Early follicular LH, FSH, testosterone and estradiol level, mid luteal phase serum progesterone level, USG lower abdomen (TVS if feasible).

\section{Ethical approval}

Ethical committee approval was taken for this study. 


\section{Statiscal analysis}

All the data collected were compiled in a tabulated manner and were analysed using statistical software (SPSS Version 16) as per nature of the data. Continuous variables like age, BMI, waist hip ratio, systolic blood pressure, diastolic blood pressure, serum fasting insulin, fasting blood sugar, total cholesterol, HDL, LDL, triglycerides, early follicular LH, FSH, estradiol, testosterone, and mid luteal (D21) progesterone were expressed as mean \pm standard deviation and compared across the 2 groups using unpaired $\mathrm{t}$ test. Categorical variable like "USG picture suggestive of polycystic ovary" at different time points, were expressed as number of patients and percentage of patients and compared with each other using Pearson's Chi square test for independence of attributes.

\section{RESULTS}

Following are the tables showing the parameters at the beginning of the study, at 6 weeks and then at 12 weeks.

Table 1: BMI (body mass index).

\begin{tabular}{|lllll|}
\hline & Group & & & \\
& Control (folic acid) & Case (myoinositol) & & \\
\cline { 2 - 4 } & Mean \pm SD & Mean \pm SD & P value & Significance \\
\hline BMI initial & $31.97 \pm 1.94$ & $31.7 \pm 1.64$ & 0.392 & Not significant \\
\hline BMI after 6 weeks & $31.51 \pm 2.11$ & $30.97 \pm 1.81$ & 0.116 & Not significant \\
\hline BMI after 12 weeks & $31.94 \pm 2.21$ & $31.15 \pm 1.74$ & 0.024 & Significant \\
\hline
\end{tabular}

Initial comparison of the difference in BMI among the candidates randomly selected in two groups was done using unpaired $t$ test. $P$ value was 0.392 , suggesting no significance.

BMI at different time points (initial, 6 weeks, 12 weeks) were expressed as mean \pm standard deviation and compared across the 2 groups using unpaired $\mathrm{t}$ test. $\mathrm{P}$ value was 0.116 at the end of 6 weeks, suggesting no significance. P value at the end of 12 weeks was 0.024 , suggesting significant result.

Waist hip ratio was also studied at different time intervals, no significant changes were found.

Table 2: Serum fasting insulin.

\begin{tabular}{|lllll|}
\hline & Group & & & \\
& Control (folic acid) & Case (myoinositol) & & \\
\cline { 2 - 5 } & Mean \pm SD & Mean \pm SD & P value & Significance \\
\hline Serum fasting insulin initial & $18.42 \pm 1.95$ & $18.5 \pm 1.93$ & 0.823 & Not significant \\
\hline Serum fasting insulin after 6 weeks & $17.85 \pm 2.05$ & $17.92 \pm 1.96$ & 0.829 & Not significant \\
\hline Serum fasting insulin after 12 weeks & $17.62 \pm 1.75$ & $17.89 \pm 1.78$ & 0.377 & Not significant \\
\hline
\end{tabular}

Table 3: Fasting blood sugar.

\begin{tabular}{|lllll|}
\hline & Group & & & \\
& Control (folic acid) & Case (myoinositol) & & \\
\cline { 2 - 5 } & Mean \pm SD & Mean \pm SD & P value & Significance \\
\hline Fasting blood sugar initial & $101.11 \pm 10.69$ & $100.53 \pm 9.9$ & 0.749 & Not significant \\
\hline Fasting blood sugar after 6 weeks & $100.48 \pm 10.71$ & $97.02 \pm 9.79$ & 0.054 & Not significant \\
\hline Fasting blood sugar after 12 weeks & $99.95 \pm 10.81$ & $94.58 \pm 9.69$ & 0.003 & Significant \\
\hline
\end{tabular}

Initial comparison of the difference in fasting blood sugar among the candidates randomly selected in two groups was done using unpaired $t$ test. $P$ value was 0.749 , which means not significant. Fasting blood sugar at different time points (initial, 6 weeks, 12 weeks) was expressed as mean \pm standard deviation and compared across the 2 groups using unpaired $t$ test. $\mathrm{P}$ value was 0.054 at the end of 6 weeks which was not significant. P value at the end of 12 weeks was 0.003 , which was significant.

Initial comparison of the difference in serum HDL among the candidates randomly selected in two groups was done using unpaired $t$ test. $P$ value was 0.669 , which means not significant. 
Serum HDL at different time points (initial, 6 weeks, 12 weeks) were expressed as mean \pm standard deviation and compared across the 2 groups using unpaired t test. $\mathrm{P}$ value was 0.074 at the end of 6 weeks which was not significant. $\mathrm{P}$ value at the end of 12 weeks was less than
0.001, which was significant. Total cholesterol, serum triglycerides and serum LDL were also studied in similar way, no significant changes were found at the end of 12 weeks.

Table 4: Serum HDL.

\begin{tabular}{|c|c|c|c|c|}
\hline & \multicolumn{4}{|l|}{ Group } \\
\hline & Control (folic acid) & Case (myoinositol) & & \\
\hline & Mean \pm SD & Mean \pm SD & P value & Significance \\
\hline HDL initial & $50.45 \pm 7.25$ & $49.93 \pm 6.64$ & 0.669 & Not significant \\
\hline HDL after 6 weeks & $51.7 \pm 7.15$ & $53.9 \pm 6.86$ & 0.074 & Not significant \\
\hline HDL after 12 weeks & $52.92 \pm 7.07$ & $57.99 \pm 6.79$ & $<0.001$ & Significant \\
\hline
\end{tabular}

Table 5: Testosterone level.

\begin{tabular}{|lllll|}
\hline & $\begin{array}{l}\text { Group } \\
\text { Control (folic acid) }\end{array}$ & Case (myoinositol) & & \\
\cline { 2 - 5 } & Mean \pm SD & Mean \pm SD & P value & Significance \\
\hline Testosterone initial & $2.58 \pm 0.36$ & $2.7 \pm 0.4$ & 0.076 & Not significant \\
\hline Testosterone after 6 weeks & $3.43 \pm 0.27$ & $3.46 \pm 0.25$ & 0.53 & Not significant \\
\hline Testosterone after 12 weeks & $3.4 \pm 0.33$ & $3.37 \pm 0.36$ & 0.648 & Not significant \\
\hline
\end{tabular}

Table 6: Mid luteal serum progesterone.

\begin{tabular}{|lllll|}
\hline & Group & & \\
& Control (folic acid) & Case (myoinositol) & \\
& Mean \pm SD & Mean \pm SD & P value & Significance \\
\hline Mid luteal (d21) progesterone initial & $4.8 \pm 1.11$ & $4.72 \pm 1.06$ & 0.649 & Not Significant \\
\hline Mid luteal (d21) progesterone after 6 weeks & $5.19 \pm 1.11$ & $5.43 \pm 1.07$ & 0.219 & Not Significant \\
\hline Mid luteal (d21) progesterone after 12 weeks & $4.77 \pm 1.14$ & $5.22 \pm 1.14$ & 0.026 & Significant \\
\hline
\end{tabular}

Table 7: USG suggestive of polycystic ovaries.

\begin{tabular}{|c|c|c|c|c|c|c|c|}
\hline \multirow{2}{*}{\multicolumn{3}{|c|}{ Group }} & \multicolumn{2}{|l|}{ Type } & \multirow{2}{*}{ Total } & \multirow[b]{2}{*}{$P$ value } & \multirow[b]{2}{*}{ Significance } \\
\hline & & & TVS & USG & & & \\
\hline \multirow{3}{*}{$\begin{array}{l}\text { Control (folic } \\
\text { acid) }\end{array}$} & \multirow{2}{*}{ PCO initial } & $\mathrm{PCO}$ & $19(79.17)$ & $34(80.95)$ & $53(80.3)$ & \multirow{2}{*}{0.861} & \multirow{2}{*}{ Not significant } \\
\hline & & Not PCO & $5(20.83)$ & $8(19.05)$ & $13(19.7)$ & & \\
\hline & Total & & $24(100)$ & $42(100)$ & $66(100)$ & & \\
\hline \multirow{3}{*}{$\begin{array}{l}\text { Case } \\
\text { (myoinositol) }\end{array}$} & \multirow{2}{*}{ PCO initial } & $\mathrm{PCO}$ & $36(81.82)$ & $16(72.73)$ & $52(78.79)$ & \multirow{2}{*}{0.394} & \multirow{2}{*}{ Not significant } \\
\hline & & Not PCO & $8(18.18)$ & $6(27.27)$ & $14(21.21)$ & & \\
\hline & Total & & $44(100)$ & $22(100)$ & $66(100)$ & & \\
\hline \multirow{3}{*}{$\begin{array}{l}\text { Control (folic } \\
\text { acid) }\end{array}$} & \multirow{2}{*}{$\begin{array}{l}\text { PCO after } 6 \\
\text { weeks }\end{array}$} & $\mathrm{PCO}$ & $20(83.33)$ & $33(78.57)$ & $53(80.3)$ & \multirow{2}{*}{0.640} & \multirow{2}{*}{ Not significant } \\
\hline & & Not PCO & $4(16.67)$ & $9(21.43)$ & $13(19.7)$ & & \\
\hline & Total & & $24(100)$ & $42(100)$ & $66(100)$ & & \\
\hline \multirow{3}{*}{$\begin{array}{l}\text { Case } \\
\text { (myoinositol) }\end{array}$} & \multirow{2}{*}{$\begin{array}{l}\text { PCO after } 6 \\
\text { weeks }\end{array}$} & $\mathrm{PCO}$ & $34(77.27)$ & $16(72.73)$ & $50(75.76)$ & \multirow{2}{*}{0.685} & \multirow{2}{*}{ Not significant } \\
\hline & & Not PCO & $10(22.73)$ & $6(27.27)$ & $16(24.24)$ & & \\
\hline & Total & & $44(100)$ & $22(100)$ & $66(100)$ & & \\
\hline \multirow{3}{*}{$\begin{array}{l}\text { Control (folic } \\
\text { acid) }\end{array}$} & \multirow{2}{*}{$\begin{array}{l}\text { PCO after } 12 \\
\text { weeks }\end{array}$} & $\mathrm{PCO}$ & $18(75)$ & $34(80.95)$ & $52(78.79)$ & \multirow{2}{*}{0.569} & \multirow{2}{*}{ Not significant } \\
\hline & & Not PCO & $6(25)$ & $8(19.05)$ & $14(21.21)$ & & \\
\hline & Total & & $24(100)$ & $42(100)$ & $66(100)$ & & \\
\hline \multirow{3}{*}{$\begin{array}{l}\text { Case } \\
\text { (myoinositol) }\end{array}$} & \multirow{2}{*}{$\begin{array}{l}\text { PCO after } 12 \\
\text { weeks }\end{array}$} & PCO & $33(75)$ & $15(68.18)$ & $48(72.73)$ & \multirow{2}{*}{0.558} & \multirow{2}{*}{ Not significant } \\
\hline & & Not PCO & $11(25)$ & $7(31.82)$ & $18(27.27)$ & & \\
\hline & Total & & $44(100)$ & $22(100)$ & $66(100)$ & & \\
\hline
\end{tabular}


Initial comparison of the difference in mid luteal (day 21) progesterone among the candidates randomly selected in two groups was done using unpaired t test. $\mathrm{P}$ value was 0.649 , which means not significant.

The D21 progesterone value at different time points (initial, 6 weeks, 12 weeks) are expressed as mean \pm standard deviation and compared across the 2 groups using unpaired t test. $\mathrm{P}$ value was 0.219 at the end of 6 weeks which was not significant. $P$ value at the end of 12 weeks was less than 0.026 , which was significant.

Early follicular LH level was studied in the two group. $\mathrm{P}$ value at the end of 6 weeks and 12 weeks were 0.71 and 0.82 , hence not significant. For early follicular FSH p value at the end of 6 weeks and 12 weeks were 0.96 and 0.10 . Similarly, $\mathrm{p}$ value for early follicular estradiol level were 0.89 at 6 and 12 weeks each, hence all were nonsignificant changes.

\section{DISCUSSION}

Our results, in many ways, corroborated with previous studies which stated that myoinositol is beneficial in obese PCOS women suffering from metabolic issues and menstrual irregularities. ${ }^{11,15}$

We found a significant effect of myoinositol on reduction of body mass index of the patients. Significant changes were found at the end of 12 weeks in the group receiving myoinositol. However, around 40 percent of those patients whose body weight got reduced during the study period, gave history of lifestyle changes (in the form of exercise and/or diet control). So, here lifestyle modification became a confounding factor and hence the decrease in body mass index of the patients in the case group cannot be solely attributed to myoinositol. We didn't find any significant effects of myoinositol on the waist hip ratio.

The mechanism of action of myoinositol is supposed to be decreasing the insulin resistance in PCOS patients. Previous studies have demonstrated a beneficial effect of myoinositol on insulin resistance in PCOS women. ${ }^{11}$ In our study no significant fall in fasting insulin level was found. However, the fasting blood sugar level of some patients were reduced in the group myoinositol was given. When the $p$ value of the results was calculated, it showed significant changes.

A metanalysis done on inositol and lipid profile showed that myoinositol helps in increasing serum HDL level in PCOS women. ${ }^{16}$ Our study corroborated with the findings. We found a significant increase in the serum HDL level in the group receiving myoinositol. No significant changes was found in other parameters of lipid profile in our study.

Previous studies have demonstrated that myoinositol is beneficial in helping a nonovulating PCOS female to ovulate. ${ }^{17}$ Our result corroborated with the same. For this we studied mid luteal serum progesterone values. It was found that during the study period of 12 weeks, the level of day 21 progesterone was increased in those group of patients who received myoinositol. When the $\mathrm{p}$ value was calculated, it showed significant results. So, a definite correlation of myoinositol with induction of ovulation was observed. However, none of the patients (who were aspiring to conceive) became pregnant during the course of study.

Regarding side effects of the drug, few patients complained of bloating sensation after having myoinositol. No reports of any drug allergy were found. Also, no other major side effects of myoinositol was noted during the course of our study.

\section{CONCLUSION}

PCOS is one of the most common endocrine disorders affecting women mostly in the reproductive age group. Several patients affected by PCOS are also affected by insulin resistance although they do not show the signs of diabetes

In this study we studied about myoinositol effects in PCOS women. Our conclusion was that myoinositol has got noticeable effects in reducing the body mass index of PCOS women. However, no significant change was noted in the waist hip ratio of the patients. Regarding the blood sugar status, no significant effect of the drug was noted over the fasting Insulin level. But the fasting blood glucose level of the patient in study group got significantly reduced as compared to those in the control group. Lipid profile was also studied, and no significant change was found in the level of serum cholesterol, triglycerides and LDL. But the level of HDL significantly increased in the group of patients receiving myoinositol. Also, there was a significant increase in the level of mid luteal serum progesterone in the group taking myoinositol. Which means it is also helpful for ovulation and hence conception in a PCOS patient. Hence we can say that myoinositol is helpful in PCOS women for improvement in their ovarian and metabolic factors.

Funding: No funding sources

Conflict of interest: None declared

Ethical approval: The study was approved by the Institutional Ethics Committee

\section{REFERENCES}

1. Homburg R. Polycystic ovary syndrome- from gynaecological curiosity to multisystem endocrinopathy. Hum Reprod. 1996;11:29-39.

2. The Rotterdam ESHRE/ASRM-Sponsored PCOS Consensus Workshop Group: Revised 2003 consensus on diagnostic criteria and long-term health risks related to polycystic ovary syndrome (PCOS). Hum Reprod. 2004;19:41-7. 
3. Nestler JE. Insulin resistance and the polycystic ovary syndrome: recent advances. Curr Opin Endocrinol Diabetes. 2000;7:345-9.

4. Genazzani AD, Lanzoni C, Ricchieri F, Baraldi E, Casarosa E, Jasonni VM. Metformin administration is more effective when non-obese patients with polycystic ovary syndrome show both hyperandrogenism and hyperinsulinemia. Gynecol Endocrinol. 2007;23:146-52.

5. Genazzani AD, Battaglia C, Malavasi B, Strucchi C, Tortolani F, Gamba O. Metformin administration modulates and restores luteinizing hormone spontaneous episodic secretion and ovarian function in nonobese patients with polycystic ovary syndrome. Fertil Steril. 2004;81:114-9.

6. Dunaif A, Xia J, Book CB, Schenker E, Tang Z. Excessive insulin receptor serine phosphorylation in cultured fibroblast and in skeletal muscle. A potential mechanism for insulin resistance in the polycystic ovary syndrome. J Clin Invest. 1995;96:801-10.

7. Ehrmann DA, Barnes RB, Rosenfield RL, Cavaghan MK, Imperial J. Prevalence of impaired glucose tolerance and diabetes in women with polycystic ovary syndrome. Diabetes Care. 1999;22:141-6.

8. Nelson VL, Qin KN, Rosenfield RL. The biochemical basis for increased testosterone production in theca cells propagated from patients with polycystic ovary syndrome. J Clin Endocrinol Metab. 2001;86:5925-33.

9. Iuorno MJ, Jakubowicz DJ, Baillargeon JP, Dillon P, Gunn RD, Allan G, et al. Effects of D-chiroinositol in lean women with the polycystic ovary syndrome. Endocr Pract. 2002;8:417-23.

10. Gerli S, Mignosa M, Di Renzo GC. Effects of inositol on ovarian function and metabolic factors in women with PCOS: a randomized double-blind placebo-controlled trial. Eur Rev Med Pharmacol Sci. 2003;7:151-9.

11. Genazzani AD, Lanzoni C, Ricchieri F, Jasonni VM. Myo-inositol administration positively affects hyperinsulinemia and hormonal parameters in overweight patients with polycystic ovary syndrome. Gynecol Endocrinol. 2008;24:139-44.

12. Kane MT, Norris M, Harrison RA. Uptake and incorporation of inositol by preimplantation mouse embryos. J Reprod Fertil. 1992;96:617-25.

13. Chiu TT, Rogers MS, Law EL, Briton-Jones CM, Cheung LP, Haines CJ. Follicular fluid and serum concentrations of myo-inositol in patients undergoing IVF: relationship with oocyte quality. Hum Reprod. 2002;17:1591-6.

14. Papaleo E, Unfer V, Baillargeon JP, De Santis L, Fusi F, Brigante C, Marelli G, et al. Myo-inositol in patients with polycystic ovary syndrome: a novel method for ovulation induction. Gynecol Endocrinol. 2007;23:700-3.

15. Papaleo E, Unfer V, Baillargeon JP, Chiu TT. Contribution of myo-inositol to reproduction. Eur J Obstet Gynecol Reprod Biol. 2009;147:120-3.

16. Tabrizi R, Ostadmohammadi V, Lankarani KB, Peymani P, Akbari M, Kolahdooz F, Asemi Z. The effects of inositol supplementation on lipid profiles among patients with metabolic diseases: a systematic review and meta-analysis of randomized controlled trials. Lipids Health Dis. 2018;17:123.

17. Papaleo E, Unfer V, Baillargeon JP, De Santis L, Fusi F, Brigante C, et al. Myoinositol in patients with polycystic ovary syndrome: a novel method for ovulation induction. Gynecol Endocrinol. 2007;23:700-3.

Cite this article as: Singh $\mathrm{P}$, Biswal S, Verma SK. A prospective randomised controlled study on the effects of myoinositol on ovarian functions and metabolic factors in women with polycystic ovarian syndrome. Int J Reprod Contracept Obstet Gynecol 2020;9:4912-7. 